\title{
31. CHLOROPHYLL DERIVATIVES IN DSDP LEG 31 SEDIMENTS
}

\author{
Earl W. Baker and G. Dale Smith, Department of Chemistry, \\ Northeast Louisiana University, Monroe, Louisiana
}

\section{INTRODUCTION AND BACKGROUND}

A continuous history of the chemical degradation of chlorophyll to petroporphyrin in marine environments is recorded in deep ocean sediments. An understanding of the reactions and mechanisms of the early phases of chlorophyll diagenesis was the goal of the investigation of a suite of Leg 15 Pleistocene cores (Baker and Smith, 1973). Next, attempts were made to unravel and extend the diagenetic scheme into the Tertiary and Upper Cretaceous through a study of Leg 22 and Leg 29 sediment cores (Smith and Baker, 1974; Baker and Smith, in press). However, samples from these legs were very low in tetrapyrrole pigment concentration, and consequently pigment characterization depended entirely upon electronic absorption spectroscopy and chromatographic properties of the compounds. Due to extremely limited pigment availability, application of mass spectroscopy was not possible.

In the present study, 11 sediment samples spanning a geologic age from early Pleistocene to Miocene were selected from Leg 31 cores (Table 1), and analyzed for tetrapyrrole content. The results reported herein represent a preliminary investigation of those samples which afforded pigment in sufficient quantity for mass spectral analysis.

\section{SAMPLES AND PROCEDURES}

The sediment samples chosen for investigation were selected from two sites in the Sea of Japan; Site 299 located in the northwest portion of the Yamato Basin, and Site 302 located on a plateau-like area of the northern flank of the Yamato Rise.

Samples 299-22-1, 299-36-1, and 302-10-0 were received and maintained in the frozen state from the Leg

TABLE 1

Sample Description

\begin{tabular}{ccclc}
\hline Sample & $\begin{array}{c}\text { Depth } \\
(\mathrm{m})\end{array}$ & $\begin{array}{c}\text { Size } \\
(\mathrm{g})\end{array}$ & Geologic Age & $\begin{array}{c}\text { Pigment } \\
\text { Yield (ppb) }\end{array}$ \\
\hline $299-22-1$ & 210 & 120 & Pleis.-Plio. & 250 \\
$299-22-4$ & 220 & 130 & Pliocene & 250 \\
$299-24-2$ & 230 & 130 & Pliocene & 240 \\
$299-30-2$ & 350 & 130 & Miocene & 70 \\
$299-30-3$ & 360 & 130 & Miocene & 70 \\
$299-36-1$ & 490 & 160 & Miocene & 80 \\
$302-10-0$ & 175 & 160 & Miocene & 100 \\
$302-10-4$ & 185 & 130 & Miocene & 60 \\
$302-11-3$ & 195 & 130 & Miocene & 60 \\
$302-12-3$ & 215 & 130 & Miocene & 50 \\
$302-14-2$ & 250 & 130 & Miocene & 40 \\
\hline
\end{tabular}

31 sample distribution chairman of the Organic Geochemistry Group. The additional samples investigated and reported in this paper were obtained by request from the Curator of the Deep Sea Drilling Project at Scripps. The latter sediments were received in an unfrozen state and extracted immediately. Preliminary data indicate no detectable difference in tetrapyrrole analysis from frozen to unfrozen core.

The general procedure described for treatment of Leg 15 (Baker and Smith, 1973) and Leg 22 (Smith and Baker, 1974) cores and the modified procedure used in the analysis of Leg 14, 20, 26, 27, and 29 sediment samples (Baker and Smith, this volume) was followed during the investigation of Leg 31 core samples. The experimental procedure is outlined in Figure 1.

Electronic absorption spectra were obtained using a Beckman ACTA CIII ultraviolet-visible linear wavelength spectrophotometer. The mass spectra were recorded using an AEI MS9 mass spectrometer equipped with a solid sample probe inlet system.

\section{SPECTRA OF FOSSIL PIGMENTS}

The youngest sample from the first site (299-22-1, Pleistocene) yielded the first detectable free base porphyrin isolated from deep ocean sediments, as characterized by the typical four-band pattern in the electronic spectrum at $620,563,528$, and $495 \mathrm{~nm}$ with intensity ratios which suggested the tetrapyrrole type DPEP (Stern, 1934). The chlorin in this sample, as in all deep ocean sediment samples investigated, occurs as the free base. The red band in the visible spectrum is slightly shifted to higher energy $(660 \mathrm{~nm})$ compared to Leg 15 Pleistocene chlorins $(663 \mathrm{~nm})$. This is probably due to increased reduction of conjugating groups reflecting the effects of depth of burial of Sample 299-22-1 (200 m). Using solid probe injection, the pigment gave a $70-\mathrm{ev}$ spectrum with molecular ions at $\mathrm{m} / \mathrm{e} 874,872,858,830$, and 816 , all of which were observed in Leg 15 Pleistocene samples. The peak at $\mathrm{m} / \mathrm{e} 872$ has been ascribed to dihydrophytol pheophorbide a, and the peaks at $\mathrm{m} / \mathrm{e} 874,858,830$, and 816 to reductive and allomerization degradation products of $\mathrm{m} / \mathrm{e} 872$ (Baker and Smith, 1973).

It has been observed that with increasing sample depth and age, the relative intensity of the reduction product peaks increase relative to $\mathrm{m} / \mathrm{e} 872$. This intensity change correlates well with red band broadening, and a shift to higher energy in the visible spectrum. This is consistent with reduction and/or removal of ring conjugating groups with extended geologic time, and the imposed increased thermal and pressure stress. 


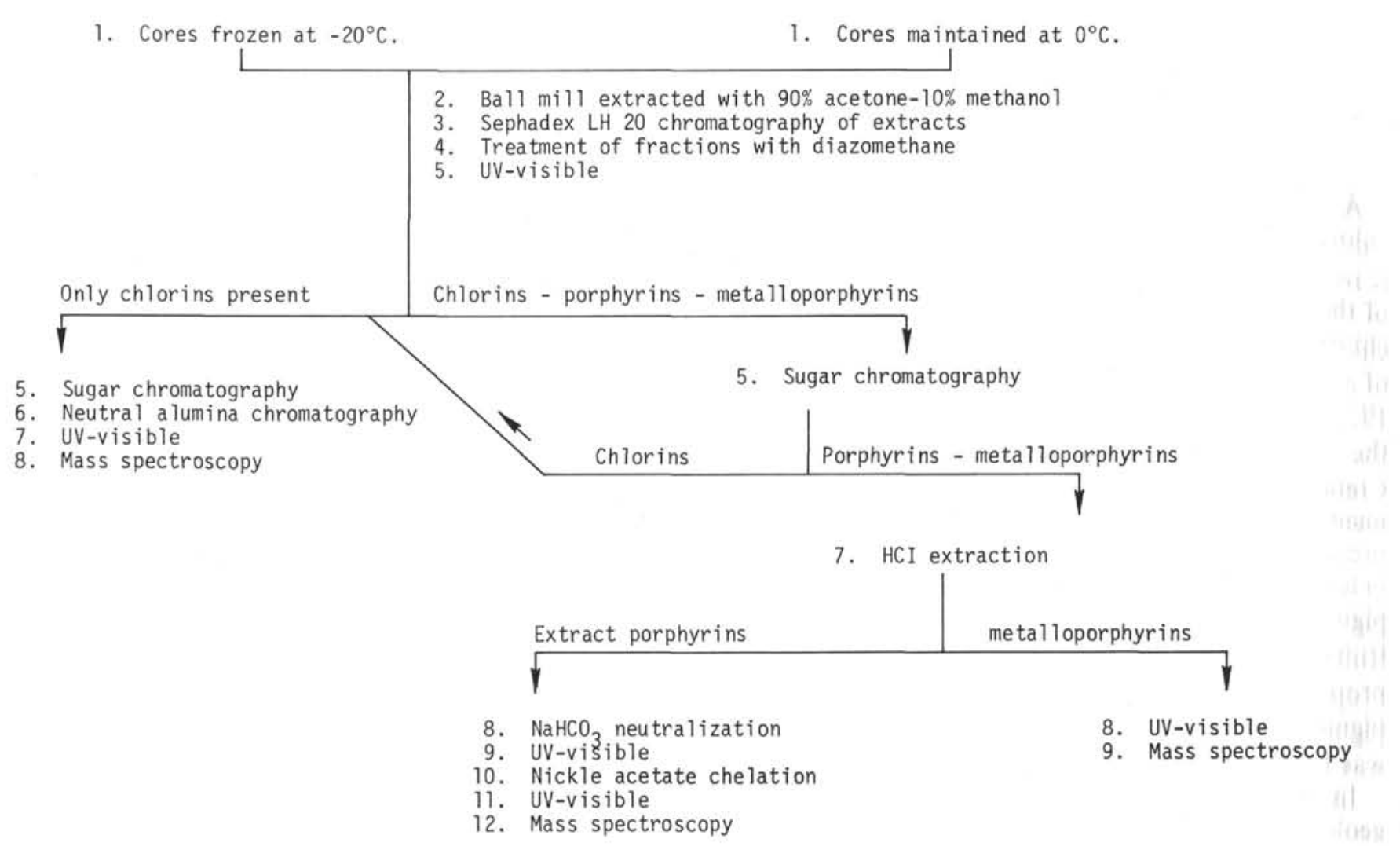

Figure 1. Experimental flow sheet.

In addition to free base porphyrin and chlorin, Sample 299-22-1 yielded, upon column chromatographic separation, a mixture of nickel porphyrins. The electronic spectrum of the mixture consisted of a near $U V$ peak at $395 \mathrm{~nm}$, and three peaks at 513,553 , and $582 \mathrm{~nm}$ of lesser intensity. A second chromatographic step afforded separation of the metalloporphyrins with $\alpha-\beta$ absorption at 513 and $553 \mathrm{~nm}$ from those absorbing at 548 and $582 \mathrm{~nm}$. Each mixture thus obtained was subjected to demetalation treatment with methanesulfonic acid (MSA) so as to determine the porphyrin class structure using characteristic absorption patterns in the 500 to 600 $\mathrm{nm}$ region of the electronic spectrum.

Demetalation of the first eluate $(\alpha-\beta$ absorption at 513 and $553 \mathrm{~nm}$ ) gave a mixture of free base porphyrins which exhibited spectral properties very similar to those of the naturally occurring free base porphyrins described above. Examination of the electronic absorption data suggests that the fraction is a mixture of tetrapyrroles consisting predominantly of DPEP-type porphyrins, with moderate amounts of Etio-type present. This is supported by the observation of a dual set of parent ions at $\mathrm{m} / \mathrm{e}$ 940-942 and 942-944 in the mass spectrum obtained for the porphyrin mixtures after laboratory conversion to the nickel chelate.

The second fraction $(\alpha-\beta$ absorption at 548 and 582 $\mathrm{nm}$ ) required a more polar solvent for elution from the neutral alumina column. Demetalation with MSA yielded a porphyrin mixture with a Rhodo-type visible spectrum. No tetrapyrrole parent ions were obtained in the mass spectrum, and therefore determination of the nature of the rhodofying substituent was not possible.

Two samples of Pliocene age taken at approximately 230 meters beneath the sediment surface (299-22-4 and 299-24-2) were combined and analyzed for tetrapyrrole content. The electronic absorption data indicated the presence of free base chlorin ( 660 and $408 \mathrm{~nm}$ ) and nickel porphyrins of the DPEP and Etio-type (553 and 395 $\mathrm{nm})$. Neither free base porphyrin nor nickel rhodoporphyrin was detected in this sample.

Miocene sediments taken approximately at 350 meters depth (Samples 299-30-2 and 299-30-3) were combined and analyzed. This visible spectrum exhibited bands at 395,553 , and $582 \mathrm{~nm}$, suggesting the presence of both Ni-DPEP, plus Ni-Etio and Ni-Rhodo-type porphyrins. The total yield of pigment was below the quantity required for purification for mass spectroscopy. At these concentration levels, absorption by impurities and metalloporphyrins could prevent observation of free base porphyrin in the electronic spectrum. Therefore, the data do not exclude the presence of small amounts of free base porphyrins, for in the next sample investigated (299-36-1) recovered from 490 meters depth, a substantial portion of the pigment was found to be free base DPEP and Etio-type porphyrins. The remaining pigment consisted of Ni-DPEP and Ni-Etio porphyrins.

Five samples of Site 302 Miocene cores were selected for analysis. Sample 302-10-0, obtained at a depth of 175 meters, yielded the four types of tetrapyrroles previously 
identified: (1) chlorin, (2) porphyrin, (3) metallo-DPEP + metallo-Etio, and (4) metallo-Rhodo. The metalloporphyrins appear to be very similar to those isolated from Site 299 cores. The red band in the chlorin spectrum was observed at $663 \mathrm{~nm}$ (similar to the Leg 15 Pleistocene chlorins) as opposed to $660 \mathrm{~nm}$ of Site 299 chlorin red bands. The mass spectrum of the very DPEP-like free base porphyrin consisted of parent ions at $\mathrm{m} / \mathrm{e} 850$ and 836 .

Due to a low organic carbon analysis and expected low tetrapyrrole yield, the remaining four Site 302 Miocene cores were combined and investigated as one sample. Again all four types of tetrapyrrole were identified; however, the relative distribution changed drastically. The chlorin decreased with a corresponding increase in total metalloporphyrin present. Within the metalloporphyrin class, Ni-Rhodo increased substantially more than Ni-DPEP + Ni-Etio.

\section{DISCUSSION}

The electronic and mass spectral data obtained in this investigation and outlined in Tables 1 and 2 are in good agreement with previously reported studies of DSDP cores. Careful review of the data at hand leads to the recognition of several consistent patterns in the modes of degradation of the chlorophyll derivatives.

As in all previous DSDP cores analyzed, no magnesium chelated tetrapyrroles were observed. From a study of Recent sediments, it is concluded that dechelation, loss of magnesium, was the first step in chlorophyll diagenesis (Smith and Baker, 1974). A comparison of the data in Table 2 with Leg 15 and Leg 22 results suggests that the pheophytins and pheophorbides formed upon chlorophyll dechelation undergo a smooth and continuous degradation through the Quaternary and into the middle Tertiary by reduction or loss of ring conjugating groups. This is indicated by the uniform shift of the red band in the visible spectra to higher energy. Also an increase in the intensity of the degradative product parent ions relative to the parent pheophorbide molecular ion was observed in mass spectra of the chlorin samples extracted from successively older sediments.

The degree of reduction of the chlorin pigments also correlates extremely well with sediment depth for a given site. However, due to the wide variation in sedimentation rate at the various drilling sites, both the sediment age and depth must be considered in comparison of pigments isolated from different sites.

The metalloporphyrin mixture, characterized by the complex absorption pattern in the 500 to $600 \mathrm{~nm}$ region of the visible spectrum, was chromatographed on neutral alumina. The first fraction eluted consisted of $\mathrm{Ni}$-DPEP and Ni-Etio-type porphyrins. A more polar solvent was required for elution of the second fraction from the neutral alumina column. Combined with the appearance of the long wavelength absorption band at $582 \mathrm{~nm}$ in the visible spectrum of the nickel chelate, and the characteristic Rhodo-type spectrum obtained on the demetaled product, this information leads to the speculation that the rhodofying group is carboxylate, possibly attached at a bridgehead carbon.

Chlorin $\mathrm{p}_{\mathrm{n}}$ compounds have been previously identified from Recent sediments. These chlorins are suggested as possible precursors of the observed Rhodo porphyrins, having C- 6 and $\gamma$-bridgehead carboxylate substituents.

\section{ACKNOWLEDGMENTS}

This research was supported by the Oceanography Section of the National Science Foundation, Grant GA-37962. The mass spectra were obtained through the cooperation of the

TABLE 2

Data Summary

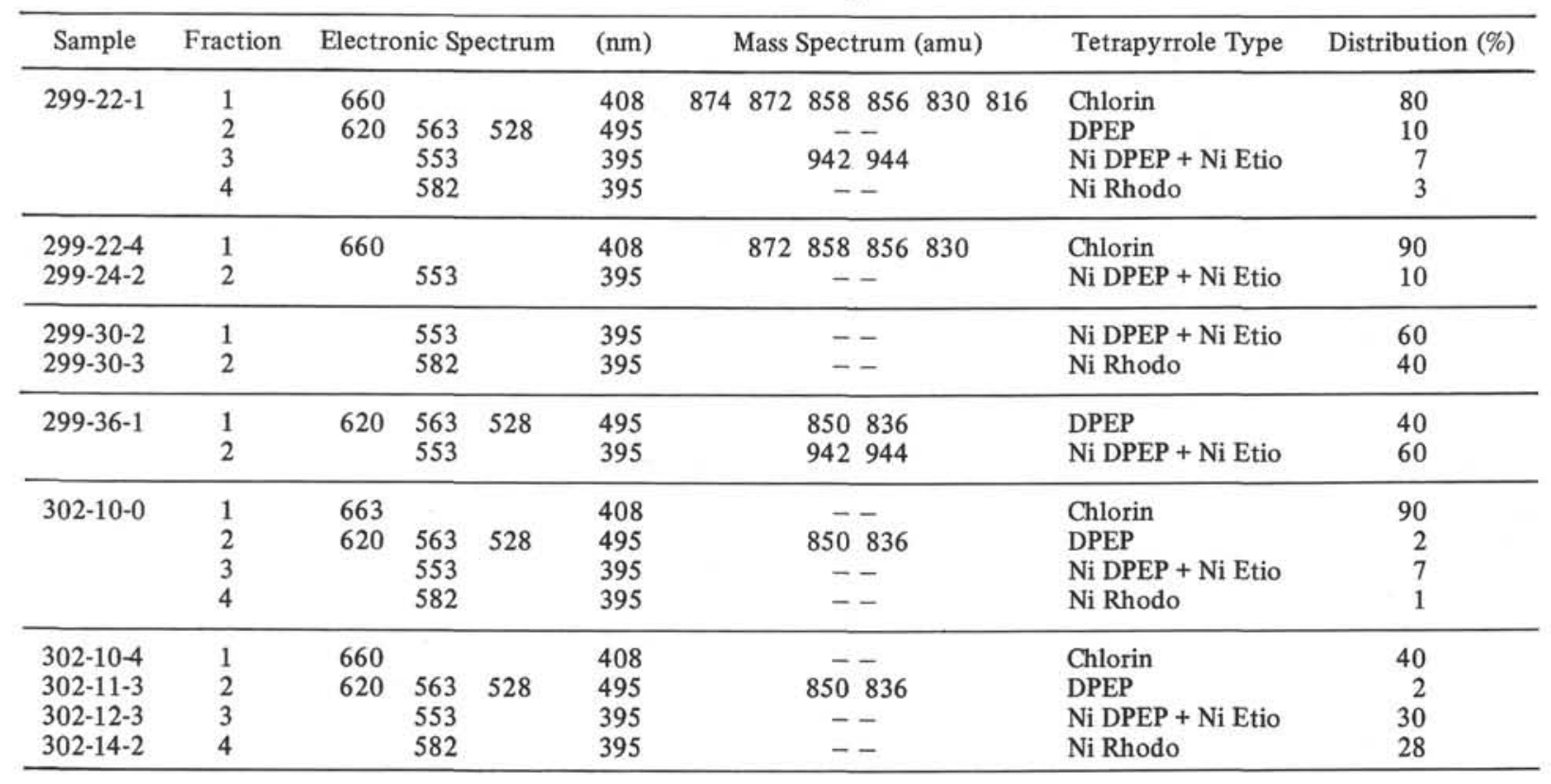


associated personnel of the Jet Propulsion Laboratory (JPL) of the California Institute of Technology (Contract Number NASA-100).

Appreciation is expressed to Heinz G. Boettger of JPL for assistance in operation of the AEI-MS9 mass spectrometer.

\section{REFERENCES}

Baker, E. W. and Smith, G. D., 1973. Chlorophyll derivatives in sediments, Site 147. In Heezen, B. C., MacGregor, I., et al., Initial Reports of the Deep Sea Drilling Project, Volume 20: Washington (U.S. Government Printing Office), p. 943.

Smith, G. D. and Baker, E. W., 1974. Chlorophyll derivatives in DSDP Leg XXII sediments. In von der Borch, C. C., Sclater, J. G., et al., Initial Reports of the Deep Sea Drilling Project, Volume 22: Washington (U.S. Government Printing Office), p. 677.

Stern, A., 1934. The light absorption of porphyrins: Z. Phys. Chem., v. A-170, p. 337. 